\title{
Proximate Determinants of Fertility in Zambia: Analysis of the 2007 Zambia Demographic and Health Survey
}

\author{
Mumbi Chola and Charles Michelo \\ Department of Public Health, University of Zambia School of Medicine, P.O. Box 50110, 10101 Lusaka, Zambia \\ Correspondence should be addressed to Mumbi Chola; mumbi24@gmail.com
}

Received 25 August 2015; Revised 18 March 2016; Accepted 23 March 2016

Academic Editor: Jonathan Haughton

Copyright ( 2016 M. Chola and C. Michelo. This is an open access article distributed under the Creative Commons Attribution License, which permits unrestricted use, distribution, and reproduction in any medium, provided the original work is properly cited.

\begin{abstract}
The role of proximate determinants in influencing fertility has been well documented worldwide. Bongaarts' aggregate model of the proximate determinants (which focuses on marriage, contraception, abortion, and sterility) has been widely used to analyse the influence of proximate determinants on fertility. In Zambia, however, there is limited understanding of their effects. Therefore, the aim of this study was to examine the effect of proximate determinants of fertility in Zambia using Bongaarts' model. This was a cross-sectional analysis of women's data from the 2007 Zambia Demographic and Health Survey (ZDHS). A total of 7,146 women aged 15 to 49 years participated in the ZDHS. Bongaarts' model was employed in the data analysis. Results showed that, overall, mean age was 27.8 years and rural-urban distribution was $56 \%$ and $44 \%$, respectively. Marriage (40\%) and postpartum infecundity (22\%) accounted for the largest inhibiting effect on natural fertility from its biological maximum of 19.10. Contraception use accounted for only 3\%. Therefore, in order to manage fertility in Zambia, policies and programmes should consider the effects of marriage, postpartum infecundity, and contraception on fertility. Without such targeted interventions, managing and maintaining population growth will remain a challenge in Zambia.
\end{abstract}

\section{Introduction}

The 2010 Census of Population and Housing reported that the average population growth rate of Zambia is $2.8 \%$, which is an increase from $2.4 \%$ recorded during the 1990-2000 intercensal period [1]. This population growth rate has been driven by a high fertility rate of 6.2 births per woman [2]. This means that a Zambian woman could give birth to an average of about 6.2 children during her reproductive life cycle [2]. Studies by Bongaarts and Potter [3] and Boermaa and Weir [4], among others, have shown that fertility rates are influenced by various factors among which are proximate determinants. Proximate determinants of fertility include those factors that directly influence fertility [3-5]. This implies that if one proximate variable changes, holding all others constant, fertility will change.

Bongaarts [6] argued that there were eight proximate determinants of fertility categorised into three broad categories:
(I) Exposure factors:

(1) Proportion married.

(II) Deliberate marital fertility control factors:

(2) Contraception.

(3) Induced abortion.

(III) Natural marital fertility factors:

(4) Lactational infecundability.

(5) Frequency of sexual intercourse.

(6) Sterility.

(7) Spontaneous intrauterine mortality.

(8) Duration of the fertile period.

These were the factors that directly influenced fertility. Their influence reduced fertility from the total fecundity rate which 
is the expected level of fertility or "natural fertility" in the absence of any deliberate controls. Bongaarts devised a quantitative framework and his analysis indicated that variations in four major factors, namely, marriage, contraception, lactation, and induced abortion, were the primary proximate causes of differences among populations [6]. This framework has since been used in various studies to analyse these four proximate determinants $[4,7]$.

Various studies employing this framework, such as studies by Letamo and Mekonnen and Worku, have shown the effect and influence that proximate determinants have on fertility [5, 8-11]. For example, an analysis of factors affecting fertility in Bangladesh showed that contraception emerged as the highest fertility reducing factor [5]. It was also shown that although the fertility reducing marriage was increasing, its effect was offset by the declining trend in the lactational infecundability period [5].

An application of Bongaarts' model to vital statistics, population census, and survey data of Peninsular Malaysia revealed that marriage postponement and contraception were the two most important proximate determinants of fertility [12]. Analysis by Mahjabeen and Khan in 2011 in Bangladesh found that contraception had the highest fertility reducing effect accounting for 51.1\% [13]. Lubaale and Kayizzi [7] analysed the 1995 and 2001 Uganda Demographic and Health Surveys using Bongaarts' model in an effort to explain fertility decline in urban areas of Uganda [7]. Their findings established that the change in the proportion of married women and postpartum infecundability due to breastfeeding had the greatest inhibiting effect on fertility in urban areas of Uganda, while contraception use contributed the least [7]. Similar results have been found in Zambia [14]. Analysis of the 1992 Zambia Demographic and Health Survey data using Bongaarts' model showed that, at that time, postpartum infecundity (37\%) contributed most towards reducing fertility followed by contraception (7\%) and marriage (5\%) [14].

Although the effects of proximate determinants have been documented in Zambia, no study has been conducted recently to show what the current scenario is with regard to proximate determinants and how this understanding interacts or informs prevailing or previously conducted interventions as they related to maternal and child health survival strategies. Previous studies, for example, by Dzekedzeke [14], were conducted prior to 1996. With the campaigns on sexual abstinence, contraception use, and breastfeeding that have been conducted since the early 1990s, it is necessary to determine how these activities may have influenced changes in the effects of proximate determinants on fertility. The effect of these factors may have changed from what was observed previously and thus may provide more recent information on the current effects of proximate determinants on fertility levels in Zambia.

Therefore, this study aimed to examine the proximate determinants of fertility in Zambia using data from the 2007 Zambia Demographic and Health Survey (ZDHS). This is the most recent Demographic and Health Survey done in Zambia. Findings from this research will provide information on proximate determinants of fertility in Zambia and how they are associated or interact with health promotion activities for maternal survival programmes relevant to fertility management. The following sections describe the methods used, the results obtained, the discussion, and conclusions drawn.

\section{Materials and Methods}

The research was based on analysis of population data from the 2007 Zambia Demographic and Health Survey (ZDHS). This is a nationally representative survey of Zambian households with a stratified representative sample of 8,000 households. All women aged between 15 and 49 years and all men aged between 15 and 59 years that were either permanent residents of the households in the sample or visitors present in the household on the night before the survey were eligible to be interviewed. The survey collected various data including levels, patterns, and trends in both current and cumulative fertility and sexual activity as well as family planning which included aspects of contraception including knowledge of specific contraceptive methods, attitudes, and behaviour regarding contraceptive use and sources of and cost of methods [2].

The research focused on analysing female fertility data. The outcome variable was live births recorded in the year preceding the survey, that is, whether the woman gave birth to a live baby in year before the ZDHS was conducted. This was a dichotomous variable with those who gave birth coded as 0 and those who did not give birth coded as 1 . Analysis of the data focused on proximate determinants as collected in the ZDHS. This included marriage, contraception, sexual activity, abstinence, postpartum amenorrhea, abortion, and menopause.

Data analysis was done by applying Bongaarts' proximate determinants model for analysing proximate determinants of fertility to female fertility data from the 2007 ZDHS. The model of Bongaarts and Potter [3] quantifies the contribution of four proximate determinants of fertility, namely, marriage, contraception, abortion, and postpartum infecundity [3]. The basic structure of the model is summarized by relating the fertility measures to the proximate determinants. The equations are shown as follows:

$$
\begin{aligned}
& \mathrm{TFR}=C_{m} \times C_{c} \times C_{a} \times C_{i} \times \mathrm{TF}(\text { see [15]). } \\
& \mathrm{TM}=C_{c} \times C_{a} \times C_{i} \times \mathrm{TF}(2) . \\
& \mathrm{TN}=C_{i} \times \mathrm{TF}(3) .
\end{aligned}
$$

TFR is the total fertility rate, TM is the total marital fertility rate, TN is the total natural marital fertility rate, TF is the total fecundity rate, and $C_{m}, C_{c}, C_{a}$, and $C_{i}$ are the indices of marriage, contraception, induced abortion, and postpartum fecundability, respectively. The indices can only take values between 0 and 1 . When there is no fertility inhibiting effect of a given intermediate fertility variable, the corresponding index equals 1 ; if the fertility inhibition is complete, the index equals 0 . These indices can be estimated from measures of the proximate variables and these estimates are given below.

2.1. Estimation of the Index of Marriage $\left(C_{m}\right)$. The index of marriage measures the inhibiting effect of marriage on 
fertility in the population. It has to be noted that the higher the level of marriage in the population the less the inhibiting effect on fertility and the reverse is true. The index of marriage is estimated using the following formula:

$$
C_{m}=\frac{\sum m(a) g(a)}{\sum g(a)},
$$

where $C_{m}$ is index of marriage, $m(a)$ is age specific proportions of married females, and $m(a)$ is gotten by dividing the number of married women of a particular age group by the number of women in the same age group. $g(a)$ is age specific marital fertility rates; $g(a)$ is gotten by dividing the births of a particular age group by the number of women in the same age group.

2.2. Estimation of the Index of Contraception $\left(C_{c}\right)$. The index of contraception measures the inhibiting effect of contraception on fertility in the population. The higher the level of contraception in the population the higher the inhibiting effect due to contraception and the lower the level of contraception the lower the inhibiting effect. The index of contraception is estimated using the following formula:

$$
C_{c}=1-1.08 * u * e,
$$

where $u$ is proportion using contraception among married women of reproductive age (15-49 years); $e$ is average use effectiveness of contraception; the coefficient 1.08 represents an adjustment for the fact that women do not use contraception if they know that they are sterile. The indices of use effectiveness proposed for particular contraceptives are pill = $0.90, \mathrm{IUD}=0.95$, sterilisation $=1.00$, and others $=0.70[3]$.

2.3. Estimation of the Index of Abortion $\left(C_{a}\right)$. The index of abortion measures the inhibiting effect of abortion on fertility in the population. In this research, the index of abortion was set at 1.0 due to lack of data. Abortion data in the ZDHS include still births and miscarriages; therefore, it was difficult to isolate the abortion data. The index of abortion is estimated using the following formula:

$$
C_{a}=\frac{\mathrm{TFR}}{\mathrm{TFR}}+b * \mathrm{TA}=\frac{\mathrm{TFR}}{\mathrm{TFR}}+0.4 *(1+u) * \mathrm{TA},
$$

where $u$ is prevalence of contraceptive use; $b$ is average number of births averted per induced abortion and $b=$ $0.4(1+u) \cdot b=0.4$ when $u=0$ and $b=0.8$ when $u=1.0$. TA is total abortion (average number of induced abortions per woman at the end of the reproductive period if induced abortion rates remain at prevailing levels throughout the reproductive period). $C_{a}=1.0$ if the TA is 0 . Therefore, the total abortion rate in this study is 1.0.

\subsection{Estimation of the Index of Postpartum Infecundability} $\left(C_{i}\right)$. The index of postpartum infecundability measures the inhibiting effect of breastfeeding or abstinence on fertility in the population. The index of postpartum infecundability in the model is estimated using the effect of breastfeeding (lactational amenorrhea) or postpartum abstinence. The index of postpartum infecundability $\left(C_{i}\right)$ is estimated as

$$
C_{i}=\frac{20}{18.5}+i
$$

where $C_{i}$ is the index of postpartum infecundability and $i$ is average duration of postpartum infecundability caused by breastfeeding or postpartum abstinence. In this research, the index of postpartum infecundability was estimated using the mean duration of breastfeeding.

The indices in Bongaarts' proximate determinants model were computed using a Microsoft Excel spreadsheet developed by the Futures Group [16] containing the necessary formulas needed to compute the indices. The spreadsheet illustrates the proximate determinants of fertility using the model developed by John Bongaarts. Information on the major proximate determinants described above was entered into the spreadsheet. Based on this information, the spreadsheet calculated the total fecundity or the biological maximum of fertility. The effects of each of the proximate determinants in reducing fertility from the total fecundity rate, or biological maximum, to the actual total fertility rate were then computed and displayed using graphs and tables. This was also done for selected background characteristics such as residence, education, and wealth quintiles. Below is the presentation of the results obtained.

\section{Results and Discussion}

Overall ( $n=7,146)$ the mean age of the female participants was 27.8 years and about $60 \%$ were reported as married, whereas only $26 \%$ were single [2]. This percentage was considered as proportion married in computing the indices of marriage. Duration of postpartum infecundability, as reported in the ZDHS report, was 13 months [2] and this is what was used in the computations to represent the average duration of postpartum infecundability. With regard to abortion data, $12.5 \%$ indicated having had a pregnancy terminated. However, this included still births and spontaneous abortions such as miscarriages. As such, determining the actual abortion figures proved problematic because of difficulties in isolating abortion data. Therefore, in the computations, abortion index was indicated as 1 to indicate absence of abortion data. Sterility contraceptive prevalence was reported as $1.3 \%$. Based on this information, total fecundity was calculated and the effects of each proximate determinant in reducing fertility from the total fecundity rate to the actual total fertility rate are displayed graphically in Figure 1.

The indices were computed and the index of marriage $\left(C_{m}\right)$ was 0.60 , while index of contraceptive use $\left(C_{c}\right)$ was 0.92 . Index of postpartum infecundability $\left(C_{i}\right)$ was 0.63 , index of abortion $\left(C_{a}\right)$ was 0.99 , and index of sterility $\left(C_{s}\right)$ was 0.94. With a total fecundity rate of 19.10 , calculating the TFR obtained the following results:

$$
\begin{aligned}
& \mathrm{TFR}=C_{m} \times C_{c} \times C_{a} \times C_{i} \times C_{s} \times \mathrm{TF} . \\
& \mathrm{TFR}=0.60 \times 0.92 \times 0.99 \times 0.63 \times 0.94 \times \\
& 19.10 \text { children/woman } . \\
& \mathrm{TFR}=6.2 \text { children/woman } .
\end{aligned}
$$


TABLE 1: Estimated proximate determinants indices and their impact on fertility reduction for Zambia, 2007.

\begin{tabular}{lcc}
\hline $\begin{array}{l}\text { Proximate determinants } \\
\text { indices }\end{array}$ & $\begin{array}{c}\text { Estimates } \\
\text { values }\end{array}$ & $\begin{array}{c}\text { Impact on fertility } \\
\text { reduction }\end{array}$ \\
\hline Index of marriage $\left(C_{m}\right)$ & 0.60 & $40.30 \%$ \\
Index of contraception $\left(C_{c}\right)^{*}$ & 0.92 & $2.90 \%$ \\
Index of abortion $\left(C_{a}\right)$ & 1.00 & $0.00 \%$ \\
$\begin{array}{l}\text { Index of postpartum } \\
\text { infecundability }\left(C_{i}\right)\end{array}$ & 0.63 & $21.80 \%$ \\
Index of sterility $\left(C_{s}\right)$ & 0.94 & $2.20 \%$ \\
\hline
\end{tabular}

* Index of abortion could not be estimated and was assumed as 1.00 due to unavailability of data on abortion.

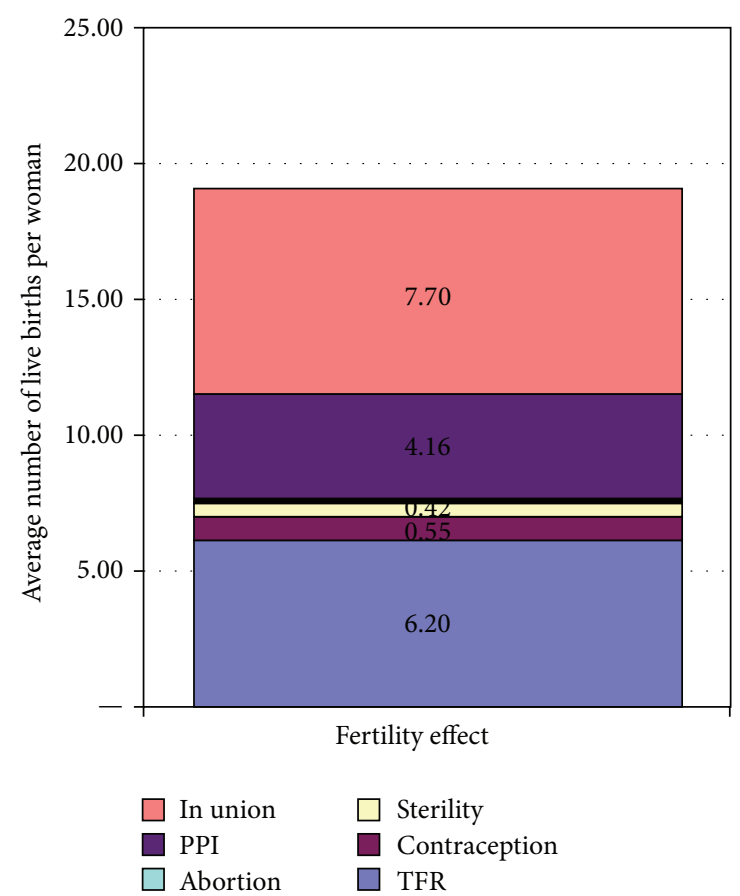

FIGURE 1: Effects of the proximate determinants on the total fertility rate.

Figure 1 shows the contribution in absolute terms of each proximate determinant to fertility reduction. The largest contributors to fertility reduction were marriage (referred to as in union in the figure) and postpartum infecundity. Marriage accounted for a reduction of 7.70 children from the biological maximum of 19.10 children per woman. Postpartum infecundity accounted for reduction of 4.2 children, while contraception accounted for a reduction of 0.55 children. Sterility accounted for a reduction of 0.42 children. In terms of percentages, the impact of each proximate determinant is displayed in Table 1.

Marriage accounted for $40.3 \%$, postpartum infecundity $21.8 \%$, contraception $2.9 \%$, and sterility $2.2 \%$ in reducing fertility from its biological maximum of 19.10 children per woman. This suggests that married women and women who breastfed longer contributed the most towards fertility reduction.
The impacts of the proximate determinants on fertility with regard to residence, education, and wealth are displayed in Table 2.

With regard to residence, the effect of marriage was higher in urban areas (51\%) than in rural areas (32\%), while the effect of postpartum infecundability was higher in rural areas (38\%) than in urban areas (26\%). The effect of contraception was higher in urban areas (8\%) than in rural areas $(6 \%)$. Marriage contributed more to fertility reduction in urban areas than in rural areas, while postpartum infecundability contributed more to fertility reduction in rural areas than in urban areas.

An inverse relationship was observed, with regard to education, between marriage and postpartum infecundability. As education level increased, the effect of marriage increases, while the effect of postpartum infecundability reduces. It was observed that, among women with no education, postpartum infecundability $(40 \%)$ contributed more towards fertility reduction than marriage (25\%), whereas among women with higher education marriage (52\%) contributed more towards fertility reduction than postpartum infecundability (18\%).

This relationship was also observed with respect to wealth. As the wealth quintile increased, the effect of marriage increased, while the effect of postpartum infecundability reduced. It was observed that, among the poorest women, postpartum infecundability (40\%) contributed more towards fertility reduction compared to marriage $(28 \%)$, whereas among the richest women marriage (56\%) contributed more towards fertility reduction than postpartum infecundability (20\%).

With contraception, however, the impact increased with increase in both education and wealth. The effect of contraception on fertility was higher among women with higher education (13\%) than among those with no education (5\%). Similarly, the effects of contraception were higher among the richest women (9\%) than among the poorest women (6\%).

The results from Bongaarts' model presented above show changes in contribution of the proximate determinants of fertility, namely, marriage, contraception, and postpartum infecundity. Results also quantify the contribution of each proximate determinant to fertility reduction in Zambia. While Dzekedzeke and Nyangu [14] found that postpartum infecundity had the most fertility reducing effect on fertility (37\%), followed by contraception (7\%) and marriage (5\%), this research found that marriage had the most effect (40\%) followed by postpartum infecundity $(22 \%)$ and contraception (3\%). Marriage, currently, has the most influence in reducing fertility in Zambia, while contraception remains the least having declined further from $5 \%$ to $3 \%$.

Majority of the women in the ZDHS were reported as married. Married women recorded the highest percentage of births (27.9) and had the highest odds of giving birth (aOR: 4.72; 95\% CI: 3.77-5.91). This could be due to traditional and cultural beliefs which promote having children after marriage. Having children outside marriage is usually frowned upon. Furthermore, with the mean age at first marriage for women aged 20-59 being 18.4 years [2], marriage as an institution is likely to contribute significantly to fertility due to women being exposed to pregnancy at an early age. 
TABLE 2: Estimated indices for the four principle determinants by selected background characteristics.

\begin{tabular}{|c|c|c|c|c|}
\hline Background characteristics & Index of marriage $\left(C_{m}\right)$ & Index of contraception $\left(C_{c}\right)$ & Index of abortion $\left(C_{a}\right)^{*}$ & $\begin{array}{l}\text { Index of postpartum } \\
\text { infecundability }\left(C_{i}\right)\end{array}$ \\
\hline \multicolumn{5}{|l|}{ Residence } \\
\hline Urban & 0.49 & 0.92 & 1.00 & 0.74 \\
\hline Rural & 0.68 & 0.94 & 1.00 & 0.62 \\
\hline \multicolumn{5}{|l|}{ Education } \\
\hline No Education & 0.75 & 0.95 & 1.00 & 0.60 \\
\hline Primary & 0.68 & 0.94 & 1.00 & 0.64 \\
\hline Secondary & 0.43 & 0.93 & 1.00 & 0.70 \\
\hline Higher & 0.48 & 0.87 & 1.00 & 0.82 \\
\hline \multicolumn{5}{|l|}{ Wealth quintile } \\
\hline Poorest & 0.72 & 0.94 & 1.00 & 0.60 \\
\hline Poorer & 0.66 & 0.95 & 1.00 & 0.61 \\
\hline Middle & 0.67 & 0.96 & 1.00 & 0.63 \\
\hline Richer & 0.56 & 0.91 & 1.00 & 0.70 \\
\hline Richest & 0.44 & 0.91 & 1.00 & 0.80 \\
\hline
\end{tabular}

${ }^{*}$ Index of abortion could not be estimated and was assumed as 1.00 due to unavailability of data on abortion.

Similar findings were found in other studies such as those by Mekonnen and Worku [8] and Raj et al. [17]. Raj et al. [17] found that there was a significant association between early marriage or child marriage and high fertility after controlling for duration of marriage. This may be the case in this research, although such analysis was not conducted. Adhikari [11] also found that age at first marriage was one of the contributing factors for high fertility.

However, despite married women recording the highest number of births, marriage had the highest fertility inhibiting effect accounting for about $40 \%$ fertility reduction from its biological maximum of 19.10 children per woman. Similar results were obtained by Islam et al. [18] who found that marriage had the largest fertility reducing effect. This effect could be attributed to considerably high contraception use among married women in Zambia with about $77 \%$ of the married women having used at least one form of modern contraception [19]. The most common modern methods included the pill (42\%), injectables (25\%), and male condom (30\%). Other methods included lactational amenorrhea (22\%) and withdrawal method (36\%) [2]. This suggests that family planning methods targeted at married women may have a huge impact on fertility reduction.

The results also showed that postpartum infecundity was the second most influential factor-with 22\%-in reducing fertility. These results are similar to those in Ethiopia [8,20, 21], Oman [18], and Malawi [22], where it was found that postpartum infecundity had a dominant inhibiting effect on fertility. Analysis of data from the World Fertility Survey (WFS) and Demographic and Health Survey (DHS) also found that index of postpartum infecundability is generally the most significant inhibitor of fertility. Although prolonged breastfeeding and postpartum abstinence are not universal in sub-Saharan Africa, they generally play an important role in spacing births and reducing total fertility [23]. This suggests that prolonged breastfeeding has the potential to contribute to fertility reduction. In India, it was found that, in the absence of breastfeeding after menstruation resumes, the risk of conception increases [3]. Singh et al. suggested that breastfeeding after menstruation resumes plays a significant role in the proximate determinants to reduce fertility [19]. Therefore, it can be argued that promotion of universal breastfeeding among women could contribute significantly to reducing fertility.

Analysis on education and wealth showed an inverse relationship between these characteristics and the indices of marriage and postpartum infecundability. This is similar to findings by Mahjabeen and Khan [13] and analysis on the World Fertility Survey and Demographic and Health Survey [23]. This could be attributed to the effects that education and wealth have on fertility. Various studies have shown that education $[11,24,25]$ and wealth [26-29] have an effect on fertility.

With regard to contraception, findings showed that contraception accounted for only $3 \%$ in the reduction of fertility from its biological maximum. These findings are consistent with those found in Uganda, where contraception had the least fertility inhibiting effects [7]. The effect of contraception considering education, wealth, and residence although increasing with wealth and education also remained the lowest. This can be attributed to low usage of contraception with only $30 \%$ of women currently using contraceptives [2]. This is despite knowledge of modern contraceptive methods being almost universal with about $97 \%$ of the women knowing of any method [2]. Since reasons for this disparity were beyond the scope of this research, further research is required to determine reasons for low utilisation of contraception. This information can be vital in improving usage of contraception and thus improve its fertility inhibiting effect.

The research was not without limitations. Abortion data was not available and therefore not included in the analysis. Availability of this data may alter the findings presented in 
this study. This research focused on the 2007 ZDHS because this was the most recent version of the ZDHS. This may have implication in that similar research on more recent data may yield different results from those presented above. It is recommended that similar research be conducted using more recent data. Another limitation was that the research focused on women and did not include men. Although men were not included in the study, they play a major role in fertility preferences which have bearing on fertility rates [30]. This is more so in rural areas, where cultural norms and values may be stronger than in urban areas. This, however, can be further investigated by conducting further research that includes males. Despite these limitations, various conclusions and recommendations can be made.

\section{Conclusion}

Proximate determinants play a key role in influencing fertility and their influence has been well documented worldwide. Their influence, however, has not been documented in Zambia since 1992. An examination of the proximate determinants of fertility in Zambia revealed that, over the period from 1992 to 2007, there has been a change in the influence of proximate determinants on fertility. Whereas in 1992 postpartum infecundity had the largest fertility inhibiting effect followed by marriage, in 2007, marriage had the largest inhibiting effect followed by postpartum infecundity. This implies that marriage contributes the most towards fertility reduction from its biological maximum. This could be explained by the increase in the proportion of married women currently using any contraception method. This proportion increased from $15.2 \%$ in 1992 to $40.8 \%$ in 2007 [2]. Furthermore, the proportion of married women across all education levels, especially women of the lower levels who use contraception, has been increasing. The documented effects of education on fertility could be contributing to married women contributing the most towards fertility reduction. The slight reduction in the overall percentage of women who were either amenorrheic, postpartum abstinent, or postpartum insusceptible may also explain why postpartum infecundability is not the most fertility inhibiting determinant.

With the Zambian government determined to manage population growth as documented in the National Population Policy, these findings provide a basis for devising intervention programmes. Marriage is both a driver and inhibitor of fertility and as an institution it contributes greatly to fertility because most children are born among married women. Therefore, programmes aimed at reduction in early marriages and teenage pregnancies should be promoted. It is necessary to advocate for policies targeting abolition of child and adolescent marriages especially in rural areas.

Married women should be encouraged to use contraception especially since they are more likely to use it. It has been shown that in the 2007 ZDHS 26.5\% of married women have unmet need for family planning (17.1\% for child spacing and $9.4 \%$ for child limiting) [2]. Contraceptive services especially those encouraging early postpartum family planning and child spacing need to be designed for these women. For couples who have the desired family sizes, sterilisation should be encouraged to prevent unplanned pregnancies. Information on these services as well as women's reproductive health and rights of women to choose their desired family size should be availed to couples as this is important for maternal and child health. Culturally sensitive means of disseminating this information and promoting these discussions should be explored.

Postpartum infecundity can greatly influence fertility. It is therefore important to promote breastfeeding for longer periods especially among urban, educated, and wealthy women who tend to breastfeed for shorter durations. Although current breastfeeding campaigns focus on the nutritional benefits to the infant, information on lactational amenorrhea as form of contraception should also be disseminated. Breastfeeding even after menstruation resumes has been found to have an influence on fertility.

Therefore, in order to reduce the population growth rate and manage fertility, of course taking into account the effects of mortality and migration, concerted efforts are required to consciously influence fertility through its proximate determinants. Without such targeted interventions, managing and maintaining population growth will remain a challenge in Zambia.

\section{Competing Interests}

The authors declare that they have no competing interests.

\section{Acknowledgments}

The authors acknowledge the support provided by the Research Support Centre at the University of Zambia, School of Medicine (UNZA-SOM), through the Southern African Consortium for Research Excellence (SACORE), which is part of the African Institutions Initiative Grant of the Wellcome Trust (Company number 2711000), a charity (no. 210183) registered in England; the National Institutes of Health (NIH) through the Medical Education Partnership Initiative (MEPI) programmatic award no. 1R24TW008873 entitled "Expanding Innovative Multidisciplinary Medical Education in Zambia" at UNZA-SOM; and the Norwegian Agency for Development Cooperation's (NORAD) Programme for Master Studies (NOMA), Project no. NOMA2010/12841, which is a tripartite cooperation between the University of Bergen, Norway, College of Medicine in Malawi, and the Department of Public Health, University of Zambia. The authors also acknowledge the various contributions made by the following people for this work: the members of the UNZA-SOM SACORE Steering Committee (Dr. Margret Maimbolwa, Dr. Paul Kelly, Dr. Helen Ayles, and Dr. Charles Michelo) and Mr. Maxward Katubulushi, Mrs. Choolwe Nkwemu Jacobs, Ms. Mutanti Simonda, and Ms. Mulemwa Mwangala arranging analytical support.

\section{References}

[1] Central Statistical Office (CSO), 2010 Census of Population and Housing: National Analytical Report, Central Statistical Office (CSO), Lusaka, Zambia, 2012. 
[2] Central Statistical Office and Ministry of Finance, Zambia Demographic and Health Survey 2007, CSO and Macro International Inc, Calverton, Md, USA, 2009.

[3] J. Bongaarts and J. E. Potter, Fertility, Biology and Behavior, Academic Press, New York, NY, USA, 1983.

[4] J. T. Boerma and S. S. Weir, "Integrating demographic and epidemiological approaches to research on HIV/AIDS: the proximate-determinants framework," The Journal of Infectious Diseases, vol. 191, supplement 1, pp. S61-S67, 2005.

[5] M. M. Islam, M. A. Islam, and N. Chakroborty, "Fertility transition in Bangladesh: understanding the role of the proximate determinants," Journal of Biosocial Science, vol. 36, no. 3, pp. 351$369,2004$.

[6] J. Bongaarts, "A framework for analyzing the proximate determinants of fertility," Population and Development Review, vol. 4, no. 1, pp. 105-132, 1978.

[7] M. Y. A. Lubaale and J. B. Kayizzi, "Using the Bongaarts model in explaining fertility decline in Urban areas of Uganda," in Proceedings of the 5th African Population Conference, Arusha, Tanzania, December 2007.

[8] W. Mekonnen and A. Worku, "Determinants of fertility in rural Ethiopia: the case of Butajira Demographic Surveillance System (DSS)," BMC Public Health, vol. 11, article 782, 2011.

[9] G. Letamo, "Contributions of the proximate determinants to fertility change in Botswana," Journal of Biosocial Science, vol. 28, no. 3, pp. 325-338, 1996.

[10] M. A. Ushie, A. A. M. Ogaboh, E. O. Olumodeji, and F. Attah, "Socio-cultural and economic determinants of fertility differentials in rural and urban Cross Rivers State, Nigeria," Journal of Geography and Regional Planning, vol. 4, no. 7, pp. 383-391, 2011.

[11] R. Adhikari, "Demographic, socio-economic, and cultural factors affecting fertility differentials in Nepal," BMC Pregnancy and Childbirth, vol. 10, article 19, 2010.

[12] N. P. Tey, S. T. Ng, and S. Y. Yew, "Proximate determinants of fertility in peninsular Malaysia," Asia-Pacific Journal of Public Health, vol. 24, no. 3, pp. 495-505, 2012.

[13] T. Mahjabeen and I. A. Khan, "Analyzing Bongaarts model and its applications in the context of Bangladesh," in Proceedings of the 19th International Congress on Modelling and Simulation, pp. 3052-3058, Perth, Australia, December 2011.

[14] K. Dzekedzeke and N. Nyangu, "Fertility patterns and their determinants," in DHS Regional Analysis Workshop fro Anglophone African, 1994.

[15] Ministry of Health, National Health Policy, Ministry of Health, Lusaka, Zambia, 2012.

[16] Futures Group, Proximate Determinants of Fertility, 2012, http://futuresgroup.com/resources/software_models/proximate determinants_of_fertility.

[17] A. Raj, N. Saggurti, D. Balaiah, and J. G. Silverman, "Prevalence of child marriage and its effect on fertility and fertility-control outcomes of young women in India: a cross-sectional, observational study," The Lancet, vol. 373, no. 9678, pp. 1883-1889, 2009.

[18] M. M. Islam, A. S. S. Dorvlo, and A. M. Al-Qasmi, "Proximate determinants of declining fertility in Oman in the 1990s," Canadian Studies in Population, vol. 38, no. 3-4, pp. 133-152, 2011.

[19] K. K. Singh, C. M. Suchindran, and K. Singh, "Effects of breast feeding after resumption of menstruation on waiting time to next conception," Human Biology, vol. 65, no. 1, pp. 71-86, 1993.
[20] G. Alene and A. Worku, "Estimation of the total fertility rates and proximate determinants of fertility in North and South Gondar zones, Northwest Ethiopia: an application of the Bongaarts' model," Ethiopian Journal of Health Development, vol. 23, no. 1, pp. 19-27, 2009.

[21] W. Mekonnen and A. Worku, "Levels and proximate determinants of fertility in Butajira district, South Central Ethiopia," Ethiopian Journal of Health Development, vol. 25, no. 3, pp. 184191, 2011.

[22] M. Palamuleni, "Fertility decline in Malawi: an analysis of the proximate determinants," Journal of Social Development in Africa, vol. 25, no. 1, pp. 9-38, 2010.

[23] L. Jolly and C. J. N. Gribble, "The approximate determinants of fertility," in Demographic Change in Sub-Saharan Africa, N. R. Council, Ed., chapter 3, The National Academies Press, Washington, DC, USA, 1993.

[24] E. Karakaya, "Socioeconomic determinants on fertility rate at an aggregate level: a linear regression model for turkish provinces," Public Knowledge Journal, vol. 6, pp. 1-6, 2014.

[25] I. Kalule-Sabiti, "Socio-economic factors affecting fertility in Kenya," South African Journal of Sociology, vol. 23, no. 2, pp. 4652, 1992.

[26] D. P. Weerasinghe and N. J. Parr, "Effect of wealth on marital fertility in Sri Lanka," Journal of Health Population and Nutrition, vol. 20, no. 2, pp. 112-119, 2002.

[27] D. Jara, T. Dejene, and M. Taha, "Determinants of high fertility status among married women in Gilgel Gibe Field Research Center of Jimma University, Oromia, Ethiopia: a case control study," Public Health Research, vol. 3, no. 2, pp. 9-17, 2013.

[28] S. A. Adebowale, S. A. Adedini, L. D. Ibisomi, and M. E. Palamuleni, "Differential effect of wealth quintile on modern contraceptive use and fertility: evidence from Malawian women," BMC Women's Health, vol. 14, no. 1, article 40, 2014.

[29] S. A. Adebowale and M. E. Palamuleni, "Childbearing dynamics among married women of reproductive age in Nigeria: reaffirming the role of education," African Population Studies, vol. 27, no. 2, pp. 301-318, 2014.

[30] L. Ibisomi and C. Odimegwu, "Understanding resolution of differential fertility preferences among couples in Nigeria," International Journal of Business and Social Science, vol. 2, no. 4, pp. 98-105, 2011. 


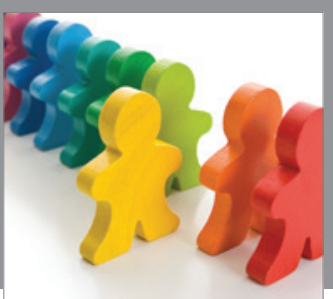

Autism

Research and Treatment
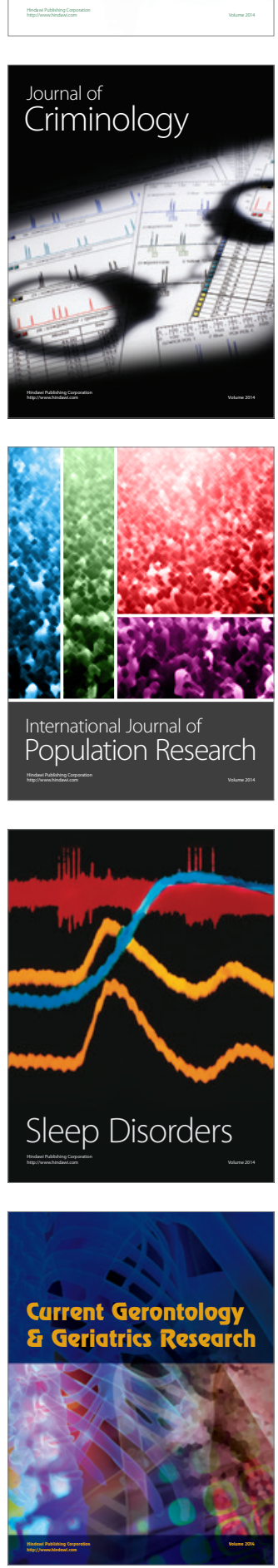

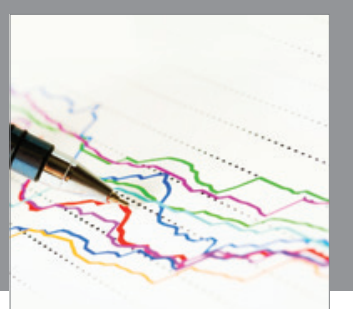

Economics

Research International
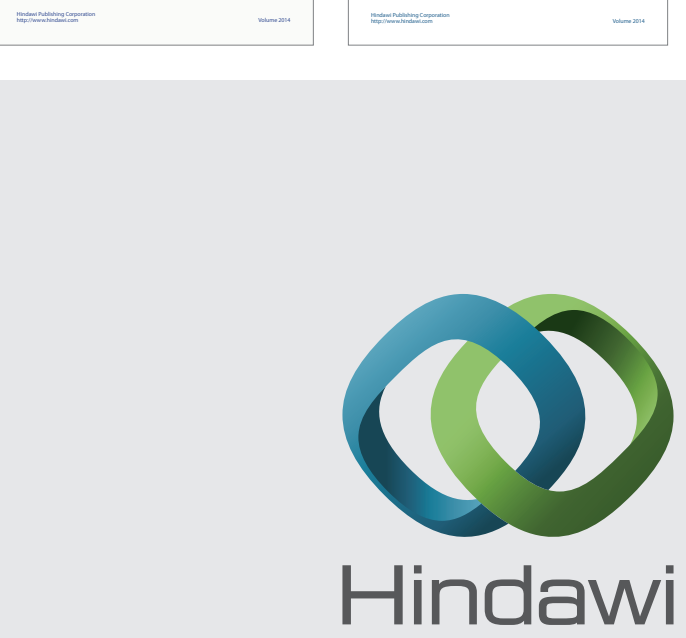

Submit your manuscripts at

http://www.hindawi.com
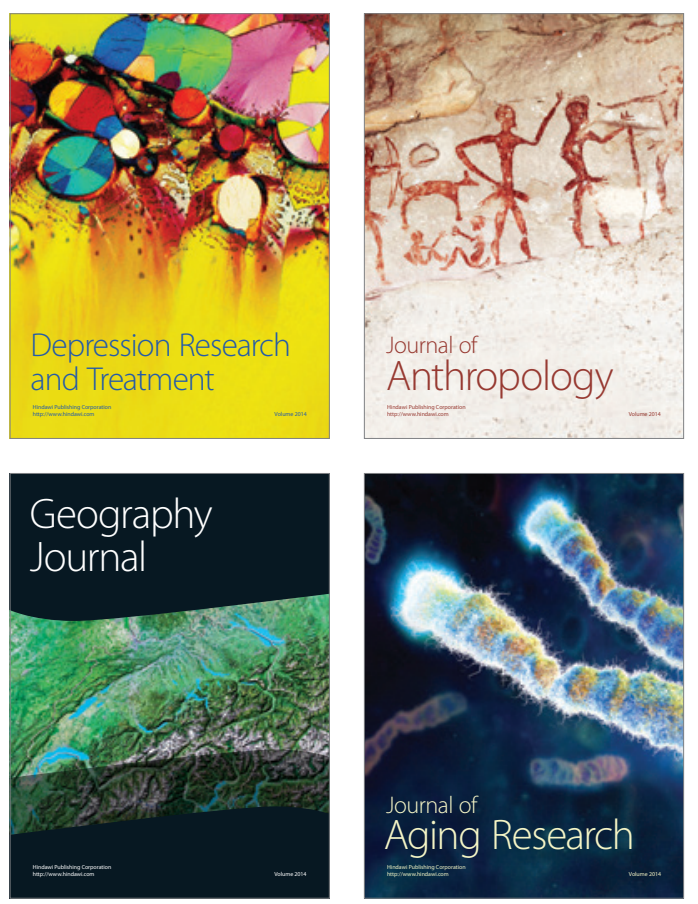
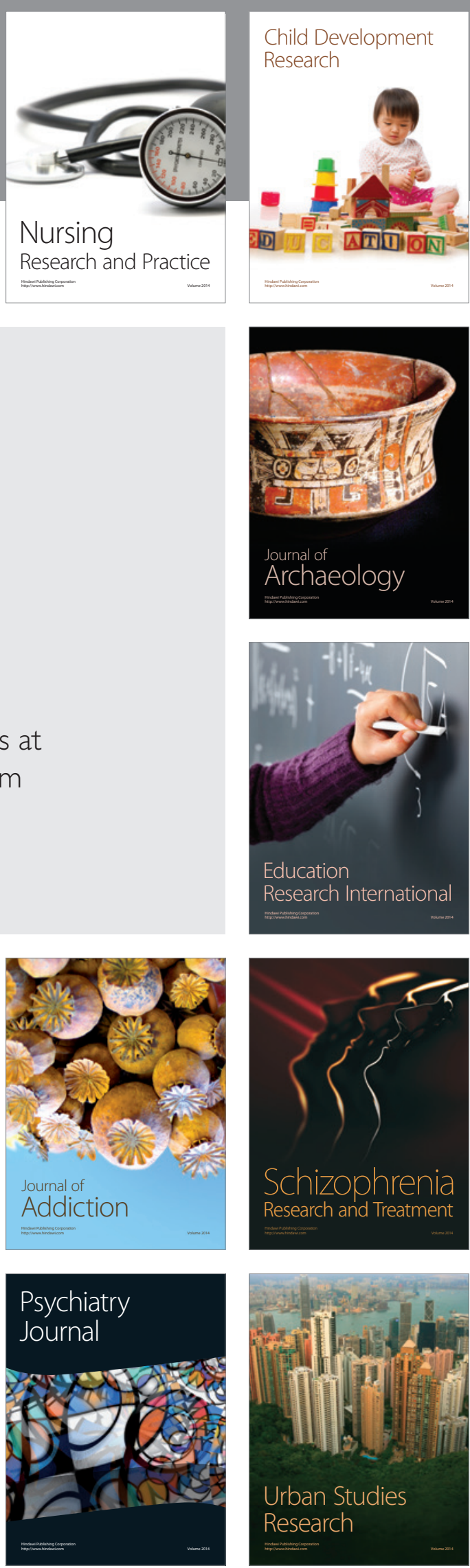